\title{
PELESAPAN SUBJEK DAN PREDIKAT PADA JUDUL-JUDUL BERITA LINE NEWS
}

\section{POPULER}

\author{
Karina Sofiananda Armaza Faraba \\ Linguistik Deskriptif, Pascasarjana, Universitas Sebelas Maret \\ Email: karina.saf4@gmail.com \\ Nugraheni Setyaningrum \\ Linguistik Deskriptif, Pascasarjana, Universitas Sebelas Maret \\ Email: nugrahenistyn@gmail.com
}

\section{Sumarlam}

Fakultas IImu Budaya, Universitas Sebelas Maret

Email: sumarlamwd@gmail.com

\begin{abstract}
Abstrak
Pada penelitian ini permasalah yang ingin dikaji adalah (1) bagaimana pelesapan subjek dan predikat pada judul-judul berita Line News Populer? (2) mengapa subjek dan predikat pada judul-judul berita Line News Populer dilesapkan? Sumber data yang digunakan adalah berita pada media Line Today. Aplikasi Line merupakan sosial media popular yang banyak digunakan masyarakat yang paham akan kemajuan teknologi. Di dalam aplikasi Line tersebut terdapat kumpulan berita terbaru yang bisa dibaca. Metode penelitian yang digunakan peneliti adalah metode penelitian analitis deskriptif. Pengumpulan data dilakukan dengan teknik simak catat. Hasil amalisis dari 10 data judul berita populer yang ditemukan dalam Line News Populer pada 4 Desember 2016 di temukan 6 klausa pada judul berita yang mengalami elipsis atau pelesapan. Tepatnya, 4 klausa mengalami pelesapan Subjek (S) dan 2 klausa mengalami pelesapan Predikat $(P)$ beserta $S+P$.
\end{abstract}

Kata Kunci: subjek, predikat, pelesapan

\begin{abstract}
The research problems are to be examined are (1) how the deletion subject and predicate in the headlines Line News Popular? (2) why the subject and predicate in the headlines Line Popular News dilesapkan? The data used is the news in the media Line Today. Application Line is a popular social media are widely used community understand the progress of technology. Inside Line application that there is a collection that can read the latest news. The method used by researchers is a descriptive analytical research methods. The data collection was
\end{abstract}


done by using refer to the note. Results of the 10 data amalisis popular news headlines found in Line News Popular on December 4, 2016 at 6 clause found in the headline that experienced an ellipsis or deletion. Precisely, 4 clause experiencing fading Subject $(S)$ and the second clause experiencing fading Predicate $(P)$ and $S+P$.

Keywords: subject, predicat, elipsis

\section{PENDAHULUAN}

Dalam ilmu bahasa atau linguistik terdapat beberapa cabang ilmu seperti fonologi, morfologi, sintaksis, semantik, pragmatik, dan analisis wacana. Semua cabang ilmu yang ada dalamilmu bahasa, mempunyai peranan dan fungsi masing-masing. Mempelajarinya pun juga harus bertahap mulai dari fonologi yang merupakan tataran linguistik yang mempelajari bunyi-bunyi bahasa, lalu morfologi yang merupakan tataran linguistik yang mempelajari satuan-satuan gramatikal di dalam kata yaitu morfem dan kata, kemudian sintaksis mempelajari satuan-satuan gramatikal di atas tataran kata, meliputi frase, klausa, dan kalimat., dsb.

Penelitian ini fokus meneliti tentang kalimat pada tataran ilmu sintaksis. Adapun kalimat yang tepat memiliki fungsi sintaksis yang lengkap. Fungsi sintaksis ialah berupa subjek, predikat, dan objek (Verhar, 2012: 165). Fungsi induk dari sebuah kalimat terdapat pada predikat.Predikat biasanya beruba kata verba yang langsung mengungkapkan suatu keadaan, kejadian, atau kegiatan.

Namun tidak semua kalimat mempunyai fungsi sintaksis yang lengkap. Salah satunya sebuah kalimat yang ada di dalam judul berita. Judul berita biasanya hanya mengungkapkan pokok dari berita yang terjadi tanpa harus menggunakan fungsi sintaksis yang lengkap pembaca sudah mengetahui makna dari judul berita tersebut. Pada penelitian ini, peneliti menggunakan sumber data 2 | ISSN: 22477-5150, e-ISSN: 2549-2195 http://journal.unesa.ac.id/index.php/jpi 
Karina Sofiananda Armaza Faraba, dkk., Pelepasan Subjek dan Predikat...(hal. 1 - 15)

dai berita online yaitu Line Today yang diambil pada kolom Line News Populer tepatnya pada bulan Desember 2016.

Peneliti memilih sumber data pada media Line Today, dikarenakan aplikasii Line merupakan sosial media popular yang banyak digunakan masyarakat yang paham akan kemajuan teknologi. Di dalam aplikasi Line tersebut terdapat kumpulan berita terbaru yang bisa dibaca. Pada umumnya berita membantu menggali informasi yang benar. Seperti halnya dalam Line Today yang menyediakan berita yang sudah terangkum berdasarkan kumpulan berita terpopuler dari situs website seperti Tribunnews.com, detik.com, kompas.com dan lain sebagainya. Berita popular di dalam Line Today berdasarkan peristiwa yang sedang hangat diperbincangkan di kalangan masyarakat, baik itu berita lokal maupun berita internasional.

Ketertarikan peneliti melakukan penelitian Pelesapan Subjek dan Predikat pada Judul-Judul Berita Line News Populer, karena sebelumnya juga sudah ada penelitian serupa Elza Lidwina (2013) penelitian tentang judul berita artikel olahraga pada detik.com dengan tujuan analisis jenis kalimat. Yulfi Nugraheni (2015) pelesapan unsur kalimat majemuk pada rubrik pendidikan dan humaniora surat kabar solopos. Dari kedua penelitian tersebut, peneliti lebih memfokuskan pada analisis fungsi dan struktur kalimat.

Berita terkadang menggunakan bahasa yang berbeda dengan bahasa lisan. Bahasa yang digunakan oleh pembuat berita atau wartawan disebut juga dengan bahasa jurnalistik. Biasanya bahasa jurnalistik itu menggunakan bahasa yang padat, jelas dan langsung ke inti berita yang akan disampaikan oleh wartawan atau pembuat berita. Oleh karena itu pembaca harus memiliki intelektualitas minimal untuk dapat mengerti maksud dari berita itu yang 
terkesan padat dan jelas tersebut. Karena tentu judul berita dalam surat kabar maupun media online tidak menggunakan fungsi sintaksis yang lengkap.

Pada penelitian ini permasalah yang ingin dikaji adalah (1) bagaimana pelesapan subjek dan predikat pada judul-judul berita Line News Populer? (2) mengapa subjek dan predikat pada judul-judul berita Line News Populer dilesapkan?

Pelesapan atau elipsis merupakan kalimat yang tidak lengkap struktur fungsi sintaksisnya. Sebuah klausa dapat dikatakan sebagai kalimat lengkap jika terdiri dari paling sedikit fungsi Subjek dan Predikat (S+P). Maka artikel penelitian ini memiliki fenomena data kalimat pada judul berita online yang akan dianalisis struktur fungsi sintaksisnya dalam pembentukan kalimat judul berita yang benar atau judul berita yang mengalami pelesapan unsur fungsi sintaksisnya.

Metode penelitian yang digunakan peneliti adalah metode penelitian analitis deskriptif. Nawawi (1991: 63) mengungkapkan bahwa metode deskriptif dapat juga diartikan sebagai prosedur pemecahan masalah yang diselidiki dengan menggambarkan atau melukiskan keadaan subjek atau objek penelitian berdasarkan fakta yang tampak sebagaimana adanya.

Pada penelitian ini penulis menggunakan sumber data berupa judul berita dalam Line News Populer yang ada pada bulan Desember 2016. Data penelitian yang digunakan berupa klausa atau kalimat pada judul-judul berita dalam Line News Populer yang ada pada bulan Desember 2016. Pengumpulan data dilakukan dengan teknik simak catat. Metode simak dilakukan untuk menyimak penggunaan bahasa. Istilah menyimak disini tidak hanya berkaitan dengan penggunaan bahasa secara lisan, tetapi juga penggunaan bahasa secara tertulis (Mahsun, 2010:92). Metode ini memiliki teknik dasar yang berupa teknik sadap. Maksud teknik sadap disini adalah menyadap penggunaan bahasa, baik secara lisan maupun tulisan. Dalam praktiknya, teknik sadap ini diikuti dengan teknik 4 | ISSN: 22477-5150, e-ISSN: 2549-2195 http://journal.unesa.ac.id/index.php/jpi 
Karina Sofiananda Armaza Faraba, dkk., Pelepasan Subjek dan Predikat...(hal. 1 - 15)

lanjutan, yaitu teknik simak libat cakap, teknik simak bebas cakap, teknik simak bebas libat cakap, dan teknik catat (Mahsun, 2010:93).

Metode simak dalam penelitian ini menggunakan teknik lanjutan berupa teknik catat. Teknik catat digunakan sebagai teknik dalam pengumpulan data. Teknik catat adalah mencatat beberapa bentuk yang relevan bagi penelitiannya dari penggunaan bahasa secara tertulis (Mahsun, 2010:93). Ada pun langkahlangkah pengumpulan data dalam penelitian ini sebagai berikut (1) mencari data berupa judul-judul berita pada media sosial Line tepatnya pada kolom Line News Populer bulan desember 2016, (2) mengunduh judul-judul berita Line News Populer bulan desember 2016 yang popular, dan (3) menganalisis pelesapan subjek dan predikat pada judul berita Line News Populer bulan desember 2016 yang populer.

Pada penelitian ini metode analisis data yang digunakan menggunakan teknik sisip dan perluasan. Menurut Sudaryanto (1993) teknik sisip dilaksanakan dengan menyisipkan "unsur" tertentu di antara unsur-unsur lingual yang ada. Kemudian teknik perluas dilaksanakan dengan memperluas satuan lingual yang bersangkutan ke kanan atau ke kiri, dan perluasan itu menggunakan "unsur" tertentu.

\section{PEMBAHASAN}

Data penelitian berupa judul berita yang diambil dari populer di news social media Line. Data diambil pada bulan november 2016 dan ditemukan sebanyak 25 data dan dipilih 10 data yang sesuai dengan berita paling populer. Analisis dilakukan secara berurutan sesuai dengan kemunculan data yang sudah didapat oleh peneliti dari Line. Analisis dilakukan untuk mengetahui jumlah dan 
struktur klausa pada judul berita dari populer di news Line. Untuk mengetahui berapa jumlah klausa yang ada, terlebih dahulu dilakukan analisis fungsi terhadap kalimat judul berita dari populer di news Line.

Pada penelitian ini peneliti mencoba membuktikan lebih lanjut tentang perbedaan judul yang ada pada judul berita news sosial media Line yang belum sesuai dengan teori fungsi dan struktur kalimat sintaksis. Ada pun yang diperoleh adalah sebagai berikut:

11. Bukan Disuntik Air, Agar Ayam Terlihat Besar, Orang-orang Ini Lakukan Hal yang Lebih Menjijikan

Bukan Disuntik Air,

\begin{tabular}{|l|l|}
\hline $\begin{array}{l}\text { Bukan } \\
\text { Disuntik }\end{array}$ & Air \\
\hline $\mathrm{P}$ & $\mathrm{O}$ \\
\hline
\end{tabular}

Agar Ayam Terlihat Besar

\begin{tabular}{|l|l|l|}
\hline Agar & Ayam & $\begin{array}{l}\text { Terlihat } \\
\text { Besar }\end{array}$ \\
\hline Konj & S & P \\
\hline
\end{tabular}

Orang-orang Ini Lakukan Hal yang Lebih Menjijikan

\begin{tabular}{|l|l|l|}
\hline $\begin{array}{l}\text { Orang- } \\
\text { orang } \\
\text { Ini }\end{array}$ & Lakukan & $\begin{array}{l}\text { Hal yang } \\
\text { lebih } \\
\text { Menjijikan }\end{array}$ \\
\hline S & P & O \\
\hline
\end{tabular}

6 | ISSN: 22477-5150, e-ISSN: 2549-2195 http://journal.unesa.ac.id/index.php/jpi 
Karina Sofiananda Armaza Faraba, dkk., Pelepasan Subjek dan Predikat...(hal. 1 - 15)

Pada data Bukan Disuntik Air, Agar Ayam Terlihat Besar, Orang-orang Ini Lakukan Hal yang Lebih Menjijikan memiliki tiga klausa. Sehingga, di katagorikan sebagai kalimat majemuk tepatnya kalimat majemuk bertingkat. Adapun struktur fungsinya, ketiga klausa tersebut memiliki struktur yang berbeda. Klausa pertama memiliki struktur fungsi sintaksis $\mathrm{P}+\mathrm{O}$. Klausa ini digolongkan sebagai kalimat tak lengkap atau mengalami elipsis atau pelesapan. Tepatnya pelesapan Subjek. Untuk klausa ke dua terdapat konjungsi di depan Subjek sebagai penanda dari kalimat majemuk bertingkat. Klausa ke dua ini memiliki struktur fungsi Konj+S+P. Karena sudah lengkap memiliki fungsi sintaksis pembentuk kalimat S+P. Sama halnya dengan klausa ketiga memiliki struktur pembentuk sintaksis yang lengkap yakni S+P+O.

12. Dunia Sorot Penangkapan Anak Presiden Soekarno Atas Tuduhan Makar

\begin{tabular}{|l|l|l|l|}
\hline Duni & Penangk & Anak & Atas \\
Soro & apan & Presiden & Tuduh \\
$\mathrm{t}$ & & Soekarno & $\begin{array}{l}\text { an } \\
\text { Makar }\end{array}$ \\
\hline S & P & O & K \\
\hline
\end{tabular}

Data ke dua ini merupakan jenis kalimat tunggal, yaitu kalimat yang terdiri dari satu klausa lengkap. Jika dilihat dari jumlah klausa. Dimana terdiri dari fungsi sintaksis yang membangun konstruksi kalimat dengan memiliki $\mathrm{S}+\mathrm{P}+\mathrm{O}+\mathrm{K}$. Dengan melihat struktur fungsi sintaksis yang membentuk klausa judul berita tersebut, maka judul berita tersebut dikatagorikan sebagai kalimat lengkap.

http://journal.unesa.ac.id/index.php/jpi ISSN: 22477-5150, e-ISSN: 2549-2195 | 7 
13. AJl Sesalkan Pengusiran Metro TV dan Kompas Saat Aksi 212

\begin{tabular}{|c|c|c|c|}
\hline AJI & $\begin{array}{l}\text { Sesalka } \\
\mathrm{n}\end{array}$ & $\begin{array}{l}\text { Pengusira } \\
\text { n Metro } \\
\text { TV dan } \\
\text { Kompas }\end{array}$ & $\begin{array}{l}\text { Saat } \\
\text { Aksi } \\
212\end{array}$ \\
\hline $\mathrm{S}$ & $P$ & 0 & $\mathrm{~K}$ \\
\hline
\end{tabular}

Data ke tiga ini merupakan jenis kalimat tunggal, yaitu kalimat yang terdiri dari satu klausa lengkap. Jika dilihat dari jumlah klausa. Dimana terdiri dari fungsi sintaksis yang membangun konstruksi kalimat dengan memiliki $\mathrm{S}+\mathrm{P}+\mathrm{O}+\mathrm{K}$. Dengan melihat struktur fungsi sintaksis yang membentuk klausa judul berita tersebut, maka judul berita tersebut dikatagorikan sebagai kalimat lengkap. Namun, terdapat Predikat Sesalkan yang merupakan Padjmaka AJl Sesalkan Pengusiran Metro TV dan Kompas Saat Aksi 212 dengan $\mathrm{P}_{\mathrm{adj}}$, menjadikan data tersebut kalimat minor. Dimana predikat dalam data menunjukkan sebuah pernyataan.

14. Polisi Dalami Penyandang Dana Dugaan Makar Rachmawati Soekarnoputri dkk

\begin{tabular}{|l|l|l|}
\hline Polisi & Dalami & $\begin{array}{l}\text { Penyandang Dana } \\
\text { Dugaan Makar } \\
\end{array}$ \\
& & $\begin{array}{l}\text { Rachmawati } \\
\text { Soekarnoputri dkk }\end{array}$ \\
\hline S & P & O \\
\hline
\end{tabular}

8 | ISSN: 22477-5150, e-ISSN: 2549-2195 http://journal.unesa.ac.id/index.php/jpi 
Karina Sofiananda Armaza Faraba, dkk., Pelepasan Subjek dan Predikat...(hal. 1 - 15)

Data ke empat tersebut merupakan jenis kalimat tunggal. Jika dilihat dari jumlah klausa. Dimana terdiri dari fungsi sintaksis yang membangun konstruksi kalimat dengan memiliki $\mathrm{S}+\mathrm{P}+\mathrm{O}$. Dengan melihat struktur fungsi sintaksis yang membentuk klausa judul berita tersebut, maka judul berita tersebut dikatagorikan sebagai kalimat lengkap. Akan tetapi melihat predikatnya berupa

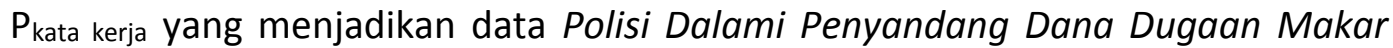
Rachmawati Soekarnoputri dkk menjadi kalimat minor. Karena predikat dalam data menunjukkan sebuah pernyataan untuk melakukan penyelidikan.

15. Lamia Airlines- Miris, Baru Terbang Perdana, Co-pilot Cantik Ini Tak Akan Pernah Kembali

Lamia Airlines- Miris,

\begin{tabular}{|l|l|}
\hline $\begin{array}{l}\text { Lamia } \\
\text { Airlines- }\end{array}$ & Miris \\
\hline S & Pel \\
\hline
\end{tabular}

Baru Terbang Perdana,

\begin{tabular}{|l|}
\hline Baru Terbang Perdana \\
\hline $\mathrm{K}$ \\
\hline
\end{tabular}

Co-pilot Cantik Ini Tak Akan Pernah Kembali

\begin{tabular}{|l|l|}
\hline Co-pilot & Tak Akan \\
Cantik Ini & Pernah \\
\hline
\end{tabular}

http://journal.unesa.ac.id/index.php/jpi ISSN: 22477-5150, e-ISSN: 2549-2195 | 9 


\begin{tabular}{|l|l|}
\hline & Kembali \\
\hline $\mathrm{S}$ & $\mathrm{P}$ \\
\hline
\end{tabular}

Jika dilihat dari jumlah klausanya, maka data kelima ini merupakan jenis kalimat majemuk bertingkat. Dimana memiliki tiga klausa yaitu, Lamia AirlinesMiris, Baru Terbang Perdana, dan Co-pilot Cantik Ini Tak Akan Pernah Kembali. Klausa pertama terdiri atas struktur fungsi sintaksis S+Pel, klausa kedua memiliki struktur fungsi sintaksis Ket saja, dan klausa ketiga terdiri dari struktur sintaksis S+P. Dari struktur fungsi sintaksis tersebut maka klausa pertama dan ke dua dapat disebut kalimat elipsis. Dimana kedua data mengalami pelesapan pada $\mathrm{P}$ dan S+P. Sedangkan pada klausa ketiga sudah bisa dikatakan sebagai kalimat lengkap, karena terdiri dari S+P.

16. Menteri Susi: Panggil Saya Bu Doktor Akan Saya Tenggelamkan

\begin{tabular}{|c|c|c|}
\hline $\begin{array}{l}\text { Menteri } \\
\text { Susi }\end{array}$ & $:$ & $\begin{array}{l}\text { Panggil Saya Bu } \\
\text { Doktor Akan } \\
\text { Saya } \\
\text { Tenggelamkan }\end{array}$ \\
\hline $\mathrm{S}$ & $P$ & $P$ \\
\hline
\end{tabular}

Data ke enam memiliki fungsi sintaksis yang diawali dengan subjek Menteri Susi, kemudian diikuti dengan predikat yang ditandai dengan tanda baca (:). Di dalam Pedoman Umum Ejaan Bahasa Indonesia yang Disempurnakan (60:2005), penggunaan tanda baca titik dua (:) adalah dalam teks drama yang menunjukkan pelaku dalam sebuah percakapan. Dalam hal ini, tanda titik dua pada data juga memiliki fungsi yang sama pada teks drama. Namun, ujaran yang 10 | ISSN: 22477-5150, e-ISSN: 2549-2195 http://journal.unesa.ac.id/index.php/jpi 
Karina Sofiananda Armaza Faraba, dkk., Pelepasan Subjek dan Predikat...(hal. 1 - 15)

diucapkan oleh penutur tidak ditulis dengan diapit tanda petik dua ("). Hal ini dikarenakan untuk memenuhi prinsip dalam bahasa jurnalistik untuk pembentukan judul kalimat. Tanda titik dua tersebut dapat menggantikan frasa berkata bahwa. Setelah predikat pada data muncul Predikat lagi. Dimana Predikat dalam data berupa pernyataan dan membentuk kalimat minor. Dengan pola $\mathrm{S}+(\mathrm{P})+\mathrm{P}$ maka data di atas termasuk kalimat lengkap.

17. Pencarian Pesawat Polri yang Jatuh Kembali Dimulai, Satu Jenazah Ditemukan

Pencarian Pesawat Polri yang Jatuh Kembali Dimulai,

\begin{tabular}{|l|l|l|}
\hline Pencarian & $\begin{array}{l}\text { Pesawat } \\
\text { Polri yang } \\
\text { Jatuh }\end{array}$ & Kembal \\
Dimulai
\end{tabular}

Satu Jenazah Ditemukan

\begin{tabular}{|l|l|}
\hline Satu Jenazah & Ditemukan \\
\hline $\mathrm{S}$ & $\mathrm{P}$ \\
\hline
\end{tabular}

Struktur fungsi sintaksis pada data ke tujuh ini memiliki dua struktur pembentuk yakni, Pel+O+P dan S+P . Karena data Pencarian Pesawat Polri yang Jatuh Kembali Dimulai, Satu Jenazah Ditemukan memiliki dua klausa yang digolongkan sebagai kalimat majemuk setara. Klausa pertama memiliki struktur Pel+O+P yang mengalami pelesapan $\mathrm{S}$, maka dikatagorikan sebagai kalimat tak 
lengkap atau elipsis. Sedangkan, untuk klausa kedua sudah merupakan kalimat lengkap.

18. Jadi Tersangka KPK, Atty Tetap Ikut Pilkada Cimahi

Jadi Tersangka KPK

\begin{tabular}{|l|l|}
\hline Jadi Tersangka & KPK \\
\hline P & O \\
\hline
\end{tabular}

Atty Tetap Ikut Pilkada Cimahi

\begin{tabular}{|l|l|l|}
\hline Atty & Tetap Ikut & $\begin{array}{l}\text { Pilkada } \\
\text { Cimahi }\end{array}$ \\
\hline S & P & O \\
\hline
\end{tabular}

Data ke delapan merupakan kalimat majemuk kombinasi. Kalimat majemuk kombinasi adalah kalimat yang terdiri dari gabungan kalimat-kalimat tersebut. Klausa pertama pada data di atas mengalami pelesapan $\mathrm{S}$, dan hanya memiliki struktur fungsi $\mathrm{P}+\mathrm{O}$. Sehingga, disebut dengan klausa tak lengkap. Sedangkan klausa ke dua memiliki struktur fungsi $\mathrm{S}+\mathrm{P}+\mathrm{O}$, jadi disebut dengan kalimat lengkap.

19. Pakai Kylie Jenner Lip Kit Palsu, Bibir Wanita Ini Bengkak Parah

Pakai Kylie Jenner Lip Kit Palsu

\begin{tabular}{|l|l|}
\hline Pakai & Kylie Jenner Lip Kit \\
& Palsu
\end{tabular}

12 | ISSN: 22477-5150, e-ISSN: 2549-2195 http://journal.unesa.ac.id/index.php/jpi 
Karina Sofiananda Armaza Faraba, dkk., Pelepasan Subjek dan Predikat...(hal. 1 - 15)

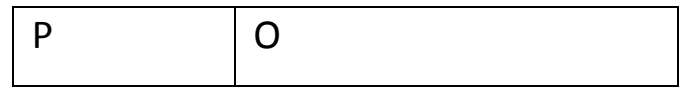

Bibir Wanita Ini Bengkak Parah

\begin{tabular}{|l|l|}
\hline $\begin{array}{l}\text { Bibir Wanita } \\
\text { Ini }\end{array}$ & $\begin{array}{l}\text { Bengkak } \\
\text { Parah }\end{array}$ \\
\hline S & Pel \\
\hline
\end{tabular}

Klausa pertama pada data tersebut juga mengalami pelesapan Subjek, sehingga disebut dengan kalimat tak lengkap. Dengan struktur fungsi $\mathrm{P}+\mathrm{O}$. Sedangkan untuk klausa ke dua juga mengalami pelesapan berupa $\mathrm{P}$, dengan struktur fungsi S+Pel. Sehingga data Pakai Kylie Jenner Lip Kit Palsu, Bibir Wanita Ini Bengkak Parah. Di katagorikan sebagai judul berita dengan klausa yang mengalami pelesapan.

20. Badut yang Dicintai Anak-anak Aleppo Tewas dalam Serangan Udara

\begin{tabular}{|l|l|l|}
\hline Badut & Tewas & dalam \\
yang & & Serangan \\
Dicintai & & Udara \\
Anak- & & \\
anak & & \\
Aleppo & & \\
\hline S & $\mathrm{P}$ & $\mathrm{K}$ \\
\hline
\end{tabular}


Data tersebut merupakan kalimat tunggal karena hanya terdiri dari satu klausa. Struktur fungsi pada data Badut yang Dicintai Anak-anak Aleppo Tewas dalam Serangan Udaraadalah S+P+K. Maka klausa judul berita tersebut di katagorikan sebagai kalimat lengkap.

\section{SIMPULAN}

Penulisan jurnalistik banyak mempertimbangkan kalimat judul yang menjadi kosntruksi awal dalam membuat sebuah berita atau artikel, guna untuk menarik pembaca maka diawali dalam pembuatan judul berita yang menarik. Oleh karena itu dalam membentuk kalimat, terutama judul sebaiknya penulis berita lebih teliti dan tetap menggunakan tata bahasa Indonesia yang baik dan benar.

Seperti dari 10 data judul berita populer yang ditemukan dalam Line News Populer pada 4 Desember 2016 di temukan 6 klausa pada judul berita yang mengalami elipsis atau pelesapan. Tepatnya, 4 klausa mengalami pelesapan Subjek (S) dan 2 klausa mengalami pelesapan Predikat (P) beserta S+P. Hal ini yang perlu diperhatikan untuk penulis berita agar lebih teliti dalam menggunakan tata bahasa Indonesia yang baik dan benar.

\section{DAFTAR RUJUKAN}

Alwi, Hasan. 2003. Tata Bahasa Baku Bahasa Indonesia. Jakarta: Balai Pustaka. Badudu, J.S. 1998. Cakrawala Bahasa Indonesia. Jakarta: Gramedia.

Chaer, Abdul. 2009. Sintaksis Bahasa Indonesia: Pendekatan Proses.Jakarta: Rineka Cipta.

Elza dan R. Niken. 2013. Judul Artikel Olahraga Portal Berita Detik.com di Twitter: Sebuah Kajian Sintaksis. Jurnal FIB UI.

Khairah, Miftahul dan Sakura Ridwan. 2014. Sintaksis Memahami Satuan Kalimat Perspektif Fungsi. Jakarta: PT Bumi Aksara.

14 | ISSN: 22477-5150, e-ISSN: 2549-2195 http://journal.unesa.ac.id/index.php/jpi 
Karina Sofiananda Armaza Faraba, dkk., Pelepasan Subjek dan Predikat...(hal. 1 - 15)

Kridalaksana, Harimurti. 2002. Struktur, Kategori, dan Fungsi dalam Teori Sintaksis. Jakarta: Universitas Katolik Atmajaya.

Mahsum. 2010. Metode Penelitian Bahasa. Jakarta: Raja Grafindo.

Oka dan Suparno.1994. Linguistik Umum. Jakarta: Direktorat Jenderal Pendidikan Tinggi Departemen Pendidikan dan Kebudayaan.

Sudaryanto. 1993. Metode dan Aneka Teknik Analisis Bahasa: Pengantar Penelitian Wahana Kebudayaan secara Linguistis. Yogyakarta: Duta Wacana University Press.

Sugiyono. 2015. Metode Penelitian Kuantitatif, Kualitatif, dan R\&D. Bandung: Alfabeta.

Sukini. 2010. Sintaksis Sebuah Panduan Praktis. Surakarta: Yuma Pustaka.

Sumarlam. 2013.Teori dan Praktik Analisis Wacana.Surakarta: Penerbit Katta.

Sutedjo dan Sumarlam. 2008. Jurnalistik Plus 1: Kiat Merentas Media dengan Ceria. Depok: Nadi Pustaka.

UNESA. 2000. Pedoman Penulisan Artikel Jurnal, Surabaya: Lembaga Penelitian Universitas Negeri Surabaya.

Verhaar. 2012. Asas-asas Linguistik Umum. Yogyakarta: Universitas Gajah Mada Press. 